Article

\title{
Simultaneously Mitigation of Acrylamide, 5-Hydroxymethylfurfural, and Oil Content in Fried Dough Twist via Different Ingredients Combination and Infrared-Assisted Deep-Frying
}

\author{
Zhonghui Han ${ }^{1,2}$, Jianxin Gao ${ }^{3}$, Shunyang Zhang ${ }^{4}$, Yan Zhang ${ }^{1, *}$ and Shuo Wang ${ }^{1}$ \\ 1 Tianjin Key Laboratory of Food Science and Health, School of Medicine, Nankai University, \\ Tianjin 300071, China; zhhan@qlu.edu.cn (Z.H.); wangshuo@nankai.edu.cn (S.W.) \\ 2 College of Food Science and Engineering, Qilu University of Technology (Shandong Academy of Sciences), \\ Jinan 250353, China \\ 3 College of Life Science, Shandong Normal University, Jinan 250014, China; 618160@sdnu.edu.cn \\ 4 College of Food Science and Engineering, Tianjin University of Science and Technology, Tianjin 300457, China; \\ jhzhang@mail.tust.edu.cn \\ * Correspondence: yzhang@nankai.edu.cn; Tel.: +86-228-5358-730
}

check for updates

Citation: Han, Z.; Gao, J.; Zhang, S.; Zhang, Y.; Wang, S. Simultaneously Mitigation of Acrylamide,

5-Hydroxymethylfurfural, and Oil Content in Fried Dough Twist via Different Ingredients Combination and Infrared-Assisted Deep-Frying Foods 2021, 10, 604. https://doi.org/ 10.3390 / foods 10030604

Academic Editor: Maria D. Guillen

Received: 20 February 2021

Accepted: 10 March 2021

Published: 12 March 2021

Publisher's Note: MDPI stays neutral with regard to jurisdictional claims in published maps and institutional affiliations.

Copyright: (c) 2021 by the authors. Licensee MDPI, Basel, Switzerland. This article is an open access article distributed under the terms and conditions of the Creative Commons Attribution (CC BY) license (https:// creativecommons.org/licenses/by/ $4.0 /)$
Abstract: The effect of main ingredients (wheat flours, polyol sweeteners, and frying oil) and infrared-assisted deep-frying on the acrylamide, 5-hydroxymethylfurfural (HMF), oil content, and physicochemical characteristics of fried dough twist (FDT) were investigated. The amount of acrylamide and HMF produced in FDT made with low-gluten flour is significantly lower than that of flour with high gluten content. Among polyol sweeteners, maltitol causes the greatest reduction in acrylamide and HMF in FDT. Moreover, the oil content of FDT was significantly reduced by optimizing the infrared-assisted deep-frying process. At last, compared with deep-frying FDT made of sucrose, infrared-assisted deep-frying FDT made of maltitol reduced acrylamide, HMF, and oil content by $61.8 \%, 63.4 \%$, and $27.5 \%$, respectively. This study clearly showed that the ingredients, flour and polyol sweeteners used to process FDT are the two major determinants of the formation of acrylamide and HMF in FDT, and infrared-assisted deep-frying can significantly affect the oil content in FDT. Simultaneously, the mitigation of the acrylamide, HMF, and oil content in FDT can be achieved by using low-gluten flour and maltitol in the ingredients, combined with infrared-assisted deep-frying.

Keywords: fried dough twist; acrylamide; 5-hydroxymethylfurfural; oil content

\section{Introduction}

Fried dough twist (FDT) is a traditional Chinese fried food, which is made by mixing wheat flour, sucrose, and other ingredients [1,2]. It is popular among consumers in China, North Korea, South Korea, and other countries, mainly due to FDT's unique color, flavor, and texture formed by the Maillard reaction.

The Maillard reaction that occurs between the amino acids (or proteins) and the reducing sugar during the heating process is critical to the formation of color, flavor, and taste. For instance, the melanoidins formed by Maillard reaction can promote the formation of attractive colors in food, and the formed pyrazine and furan have a pleasant nutty taste and caramel aroma in food [3,4]. The Maillard reaction can also induce the formation of high molecular weight polymers by affecting the structure of the proteins, resulting in the increase in hardness of protein bars [5,6].

Nevertheless, the Maillard reaction can also promote the formation of potentially harmful Maillard reaction products (MRPs) such as acrylamide and 5-hydroxymethylfurfural (HMF) in foods [1,2,7-9]. Acrylamide in food is mainly generated by the reaction of asparagine with reducing sugars (glucose and fructose) as precursors (Figure 1) [10]. Many 
studies have demonstrated that acrylamide has genotoxicity, neurotoxicity, and carcinogenicity effects on human cells and animals [11,12]. HMF is mainly formed by the Amadori rearrangement product of hexose or by the direct dehydration of sugars when the $\mathrm{pH}$ value is equal to or less than 7 (Figure 1) [13,14]. HMF has also been confirmed to have genotoxicity, neurotoxicity, and carcinogenicity effects on human cells and animals [11,12]. HMF was confirmed to have carcinogenicity and genotoxicity in animals and human cells $[8,15]$. Acrylamide and HMF have been detected in many food products, especially in high-temperature processing foods such as frying (fried potato products), baking (biscuits and bread), and roasting (roasted coffee) $[9,12,16,17]$. The content of acrylamide in heated foodstuffs can reach up to $4804 \mathrm{\mu g} \mathrm{kg}^{-1}$ [18]. To reduce the risk of potentially harmful substances that possibly cause adverse effects on human health, researchers have been actively seeking approaches to different ways of processing foodstuffs. For example, reducing asparagine in potatoes can reduce the formation of acrylamide in French fries, and adding additives can reduce the formation of acrylamide and HMF in the biscuit [19-21].<smiles>C=CC(N)=O</smiles>

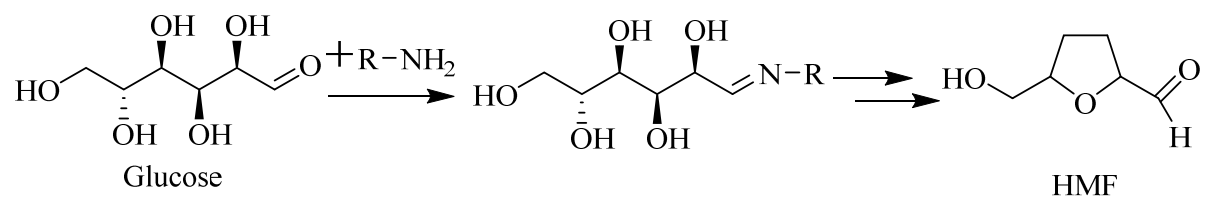

Figure 1. The formation of acrylamide (AA) and hydroxymethylfurfural (HMF).

Besides, deep-fried FDT contains a lot of fried oil. Studies have shown that an excessive intake of high-fat foods can cause a variety of diseases, such as obesity, cardiovascular, and Alzheimer's disease. Therefore, it is an inevitable development to reduce the oil content in FDT to meet consumer demand for healthy foods [22]. There are many ways to reduce the oil content in fried foods, many of which are based on the relationship between food moisture content and oil content during the frying process. The chickpea flour-based snack food and potato slices can be pretreated by an infrared, oven, and other different methods to reduce the moisture content and the water-oil transfer gradient during the frying process, thereby reducing the oil content of the food $[23,24]$.

As mentioned above, many factors affect physicochemical characteristics, potentially harmful MRPs, and oil content in foods, including recipe ingredients, processing methods, processing temperature (time), and so on. However, little is known about the effect of the main ingredients and processing methods on potentially harmful MRPs, oil content, as well as related physicochemical characteristics of FDT during the manufacturing process. Therefore, the main objectives of this study were to (i) evaluate the effects of wheat flours, polyol sweeteners, frying oil on acrylamide, HMF, oil content, and physicochemical characteristics during the manufacturing process of FDT, and (ii) to develop a strategy of infrared-assisted deep-frying to reduce the formation of unhealthy MRPs and oil content for enhancing the safety and quality of FDT.

\section{Materials and Methods}

\subsection{Materials}

Standards of 5-hydroxymethylfurfural (HMF), acrylamide, and $d_{3}$-acrylamide were obtained from Sigma-Aldrich (St.Louis, MO, USA). Zinc acetate, petroleum ether, formic acid, potassium hexacyanoferrate, n-hexane, petroleum ether, acetonitrile (HPLC grade), and methanol were purchased from J\&K Scientific (Beijing, China). 
Wheat flour (low-gluten flour, medium-gluten flour, and strong-gluten flour) were purchased from Weifang Kite Flour Co., Ltd. (Weifang, Shangdong, China). Yeast was provided by Angel Yeast Co., Ltd. (Yichang, Hubei, China). Sucrose was purchased from Guangzhou Fuzheng Donghai Food Co., Ltd. (Guangzhou, Guangdong, China). Maltitol, sorbitol, and lactitol were provided by Shandong Green Construction Biotechnology Co., Ltd. (Dezhou, Shangdong, China). Palm oil, soybean oil, and rapeseed oil were purchased from COFCO Corporation (Beijing, China). Shortening was obtained from Shanghai Gaofu Longhui Food Co., Ltd. (Shanghai, China).

\subsection{Preparation of FDT}

The formula of FDT is provided by the food manufacturer with minor modifications. Ingredients and their weight proportions were $100 \mathrm{~g}$ of wheat flour, $10 \mathrm{~g}$ of sweeteners, $1 \mathrm{~g}$ of dry yeast, $5 \mathrm{~g}$ of shortening, and $40 \mathrm{~mL}$ of water. Firstly, the dough was kneaded, and $1 \mathrm{~g}$ of yeast and $2 \mathrm{~g}$ of sweetener was mixed into $40 \mathrm{~mL}$ of water (temperature $40{ }^{\circ} \mathrm{C}$ ) to form a solution, then the solution was slowly added to $100 \mathrm{~g}$ of flour and continuously stirred for $2 \mathrm{~min}$, followed by $5 \mathrm{~g}$ of shortening added, and then kneaded repeatedly until the dough surface was smooth. The dough was rested in a proofing cabinet $\left(37^{\circ} \mathrm{C}, 85 \%\right.$ $\mathrm{RH}$ ) for $30 \mathrm{~min}$. For shaping, $8 \mathrm{~g}$ of sucrose was added to the dough and kneaded for $4 \mathrm{~min}$, then kneaded into a cylindrical strip with a diameter of $1 \mathrm{~cm}$. The dough was then divided by sections and cut by $15 \mathrm{~cm}$, folded in half, and twisted into a rope shape. Finally, the shaped-dough was fried with oil at $160{ }^{\circ} \mathrm{C}$ (or infrared equipment pretreatment (Meibo, Zhenjiang, China) deep-frying).

\subsection{Quantification of Acrylamide in FDT}

Acrylamide of the sample was determined according to a previously performed method [25], with minor modifications.

A total of $10 \mathrm{mg} / \mathrm{L}$ of $d_{3}$-acrylamide internal standard solution $(10 \mu \mathrm{L})$ and deionized water $(9 \mathrm{~mL})$ were added to $15 \mathrm{~mL}$ plastic centrifuge tubes containing $1.0 \mathrm{~g}$ of FDT powder, followed by $0.5 \mathrm{~mL}$ of Carrez I and II reagent. The mixed solutions were shaken at $40{ }^{\circ} \mathrm{C}$ for $30 \mathrm{~min}$, and then centrifuged at $5000 \times \mathrm{g}$ for $10 \mathrm{~min}$, finally, the supernatant was taken for purification. The n-hexane $(10 \mathrm{~mL})$ was added to the supernatant and shaken for $10 \mathrm{~min}$, and then removed, followed by purification of the acrylamide using a pretreated Waters Oasis HLB SPE column $(200 \mathrm{mg}, 30 \mu \mathrm{m})$. The prepared sample was centrifuged at $8000 \times g$ for 10 min to obtain the supernatant, which was then filtered by a $0.22 \mu \mathrm{m}$ nylon filter and used for liquid chromatography-mass spectrometry (LC-MS/MS) analysis.

LC-MS/MS analysis was performed on an Agilent 1200 LC system (Agilent, Waldbronn, Germany) connected to an Agilent 6410 triple-quadrupole mass spectrometer (Agilent, Waldbronn, Germany) in ESI+ and MRM mode. The nebulizer, drying, and collision gas was nitrogen. The nebulizer pressure, drying gas flow rate, and capillary voltage were $40 \mathrm{psi}, 10 \mathrm{~L} \cdot \mathrm{min}^{-1}\left(350^{\circ} \mathrm{C}\right)$, and $4 \mathrm{kV}$, respectively. The analytical column was an Agilent ZORBAX Eclipse on a C-18 column $(2.1 \times 150 \mathrm{~mm}, 3.5 \mu \mathrm{m})$ maintained at $35^{\circ} \mathrm{C}$. The mobile phase was methanol:water $(5: 95, v / v)$ mixture with a flow rate of $0.2 \mathrm{~mL} \cdot \mathrm{min}^{-1}$, running for $15 \mathrm{~min}$. The injection volume was $2 \mu \mathrm{L}$. $\mathrm{m} / \mathrm{z} 72.2 \rightarrow \mathrm{m} / \mathrm{z} 55.4$ and $\mathrm{m} / \mathrm{z} 75.3 \rightarrow \mathrm{m} / \mathrm{z}$ 58.4 transitions for acrylamide and $d_{3}$-acrylamide, respectively. The limit of detection (LOD) in samples was $6 \mu \mathrm{g} \cdot \mathrm{kg}^{-1}$ and the limit of quantification (LOQ) was $16 \mu \mathrm{g} \cdot \mathrm{kg}^{-1}$.

\subsection{Quantification of HMF in FDT}

The analysis of HMF was carried out according to our previously established method [25,26], with minor modifications. For a sample of $1 \mathrm{~g}$ of FDT powder in plastic centrifuge tubes, $8 \mathrm{~mL}$ of deionized water and $0.5 \mathrm{~mL}$ of Carrez I and II solutions were added. The mixtures were vortexed for $3 \mathrm{~min}$ and then shaken for $30 \mathrm{~min}$ at $40^{\circ} \mathrm{C}$, subsequently, centrifuged at $5000 \times g$ for $10 \mathrm{~min}$, to obtain clear supernatants. The HMF in supernatants was purified by applying the Waters Oasis HLB SPE cartridges $(200 \mathrm{mg}, 30 \mu \mathrm{m})$. The prepared samples were filtered by a $0.22 \mu \mathrm{m}$ nylon filter, and then analyzed with HPLC. 
Instrumental analysis was performed using a Shimadzu HPLC system (Shimadzu, Kyoto, Japan) consisting of a CBM-20A system controller, two LC-20AT pumps, a DGU-20A degasser, an LC-20A UV detector, and a CTO-20AT column oven. The analysis system was equipped with a Thermal ODS C18 analysis column $(4.6 \mathrm{~mm} \times 250 \mathrm{~mm}, 5 \mu \mathrm{m})$. The temperature of the column oven was set to $35^{\circ} \mathrm{C}$. The UV detection wavelengths was $284 \mathrm{~nm}$. The mobile phase was acetonitrile:water $(5: 95, v / v)$ at a flow rate of $0.6 \mathrm{~mL} \cdot \mathrm{min}^{-1}$, and the run time was 20 min per sample. The injection volume was $20 \mu \mathrm{L}$. LOD and LOQ of the samples were $0.06 \mathrm{mg} \cdot \mathrm{kg}^{-1}$ and $0.15 \mathrm{mg} \cdot \mathrm{kg}^{-1}$, respectively.

\subsection{Analysis of Oil Content}

The soxhlet extraction method was used for the determination of oil content in the sample.

\subsection{Analysis of Moisture Content and Water Activity}

The moisture content of the sample $(3 \mathrm{~g})$ was determined by oven drying at $105{ }^{\circ} \mathrm{C}$ for $1 \mathrm{~h}$ under atmospheric pressure. The water activity $\left(\mathrm{a}_{\mathrm{w}}\right)$ of the sample $(5 \mathrm{~g})$ was measured using an $\mathrm{a}_{\mathrm{w}}$ instrument (LabSwift-aw, Novasina, Switzerland). Each measurement was repeated three times.

\subsection{Analysis of FDT Color}

The color measurements of FDT were carried out with a Konica Minolta CM-5 spectrocolorimeter (Tokyo, Japan). The values were recorded according to three independent parameters of CIE-L* (lightness, from $0=$ black to $100=$ white), $a^{*}\left(+a^{*}=\right.$ redness, $-a^{*}=$ greenness $)$, and $b^{*}\left(+b^{*}=\right.$ yellowness, $-b^{*}=$ blueness $)$. Each sample was analyzed six times. $\Delta \mathrm{E}^{*}$ index was calculated according to Equation (1), which allows for evaluating the total color changes in the samples. The browning index (BI) was calculated using parameters of CIE-L* $\mathrm{a}^{*}, \mathrm{~b}^{*}$, according to Equations (2) and $(3)[27,28]$.

$$
\begin{gathered}
\Delta \mathrm{E} *=\sqrt{\Delta \mathrm{a} *^{2}+\Delta \mathrm{b} *^{2}+\Delta \mathrm{L} *^{2}} \\
\mathrm{BI}=[100(\mathrm{x}-0.31)] / 0.17 \\
\text { where } \mathrm{x}=(\mathrm{a} *+1.75 \mathrm{~L} *) /(5.645 \mathrm{~L} *+\mathrm{a} *-0.3012 \mathrm{~b} *)
\end{gathered}
$$

\subsection{Analysis of FDT Texture}

Texture characterization of FDT was carried out at room temperature by using a texture meter TA-XTplus (Stable Micro Systems, Surrey, UK), applying a three-point bending probe (HDP/3PB) for the test sample. The probe pre-test speed and test speed were set at $1.0 \mathrm{~mm} \cdot \mathrm{s}^{-1}$, the posttest speed was set at $10 \mathrm{~mm} \cdot \mathrm{s}^{-1}$, the probe depression distance was set to $12 \mathrm{~mm}$, and the trigger force was $5 \mathrm{~g}$. The maximum peak value during compression was recorded as hardness and the first peak value during compression was recorded as fracturability.

\subsection{Statistical Analysis}

Data were expressed as the mean \pm standard deviation (SD) for three samples from each raw material, except for special annotations. Experimental data was performed in the analysis of variance (one-way ANOVA) by the Duncan test $(p<0.05)$. All statistical treatments were carried out using SPSS for Windows version 19.0 (SPSS Inc., Chicago, IL, USA).

\section{Results and Discussion}

\subsection{Effect of Main Ingredients on Acrylamide and HMF in Fried Dough Twist (FDT)}

FDT was formulated with the same recipes except for flour to evaluate the effect on the formation of acrylamide and HMF. The effect of flour with different gluten content on the content of acrylamide and HMF in FDT is shown (Figure 2a). The content of 
acrylamide in FDT processed by strong-gluten flour was the highest $(p<0.05)$, which is $275.22 \pm 8.15 \mu \mathrm{g} / \mathrm{kg}$, while the highest content of HMF $(1789.95 \pm 32.42 \mu \mathrm{g} / \mathrm{kg})$ in FDT was processed by medium strong-gluten flour. The increase in acrylamide may be ascribed to elevated levels of protein, which is similar to the previous report that crude protein may increase the acrylamide content in yeast-fermented bread [29]. Besides, the content of HMF is about several times that of acrylamide, which indicated that HMF was more easily generated than acrylamide in the thermal processing of FDT.
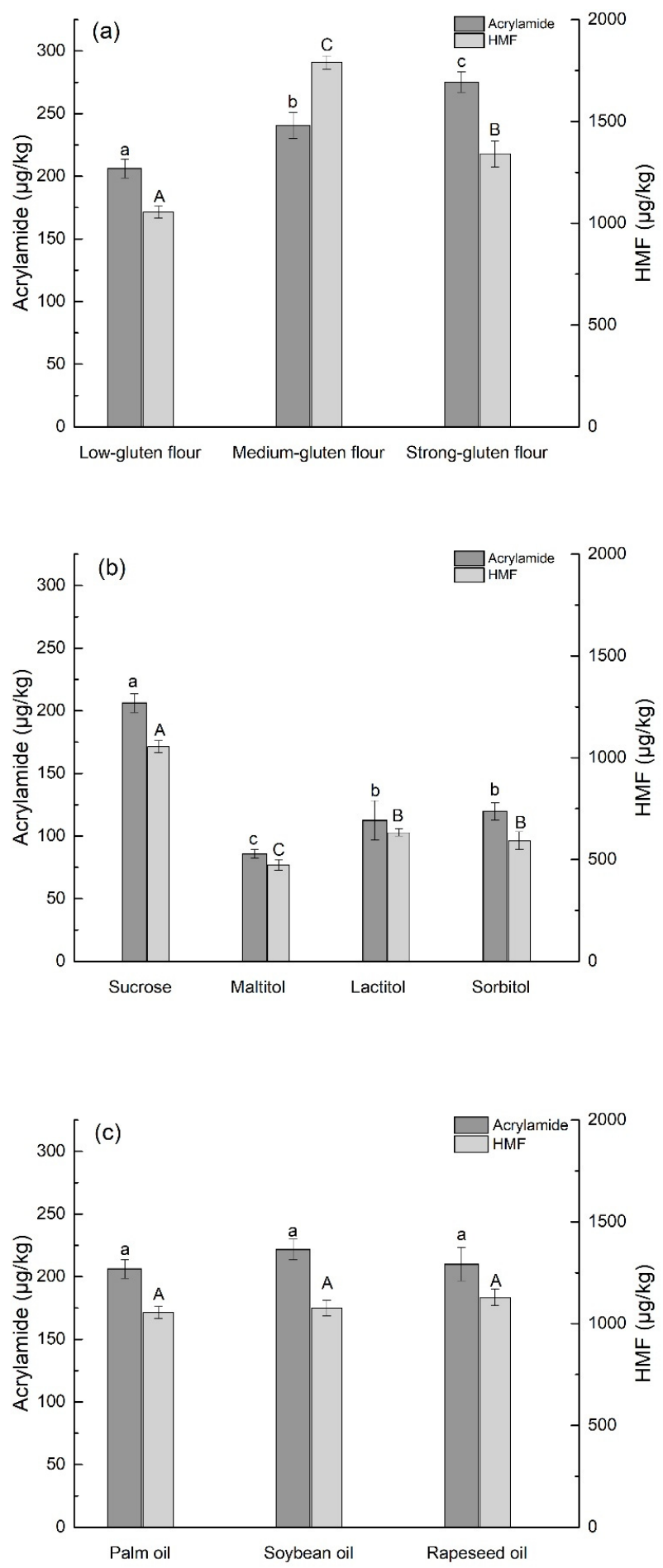

Figure 2. Effect of different ingredients (wheat flours (a), polyol sweeteners (b), and frying oil (c)) on acrylamide and 5-hydroxymethylfurfural (HMF) in fried dough twist (FDT). The different lowercase and uppercase letters represent significant difference $(p<0.05)$. 
The influence of different polyol sweeteners instead of sucrose on the formation of acrylamide and HMF in FDT is shown in (Figure 2b). Compared with sucrose, the contents of acrylamide and HMF in FDT with different polyol sweeteners (maltitol, lactitol, and sorbitol) was significantly reduced $(p<0.05)$. The main reason may be that the polyol sweeteners in the dough cannot be decomposed or degraded into reducing sugars, so that it cannot participate in the Maillard reaction to form potentially harmful MRPs $[9,30]$. The amount of acrylamide and HMF formed in FDT with maltitol was the lowest, and the contents were $85.68 \pm 13.38$ and $474.08 \pm 26.16 \mu \mathrm{g} / \mathrm{kg}$, respectively. These results suggested that the addition of polyol sweeteners instead of sugar is an effective way to mitigate potentially harmful MRPs. The effect of soybean oil and rapeseed oil on potentially harmful MRPs in FDT is shown in (Figure 2c). The results revealed that different types of frying oil have no significant effect on the formation of acrylamide and HMF in FDT. The above results indicated that the use of low-gluten flour and maltitol in the ingredients made of FDT can significantly reduce the formation of acrylamide and HMF.

\subsection{Effect of Main Ingredients on Physicochemical of Fried Dough Twist (FDT)}

In the present study, samples of different formulas were prepared to investigate the effects of ingredients on the physicochemical characteristic analysis of the FDT. The values of the influence of wheat flours, polyol sweeteners, and frying oil on the moisture content, water activity $\left(\mathrm{a}_{\mathrm{w}}\right)$, color, and texture profile in the FDT are presented in Table 1.

The data showed that the moisture content of FDT made with low-gluten flour was significantly higher than that of FDT made with strong-gluten flour $(p<0.05)$. The possible reason is that the increase of surface voids in strong-gluten flour FDT dough, which makes the contact area between FDT and frying oil increase, resulting in more water evaporation and reducing the moisture content in the FDT. While the results revealed that different gluten flours had no significant effect on $\mathrm{a}_{\mathrm{w}}$ of FDT, and demonstrated that FDT has low free water content and good storage properties [31]. Polyol sweeteners added had no significant effect on moisture content and $\mathrm{a}_{\mathrm{w}}$ of FDT compared with the addition of sucrose. Our observation is inconsistent with previous reports. Zoulias et al. showed that the addition of polyol sweeteners in cookies has a higher moisture content and $\mathrm{a}_{\mathrm{w}}$ value than the addition of sucrose [32]. This may be due to the oil more easily penetrating the food for heat transfer, which greatly reduces the moisture retention properties of polyol sweeteners during frying. Palm oil, soybean oil, and rapeseed oil were used in the fried dough respectively, and the results showed that they have no significant difference in the moisture content and $\mathrm{a}_{\mathrm{w}}$ in FDT.

The values of the color parameters $\left(\mathrm{a}^{*}, \mathrm{~b}^{*}, \mathrm{~L}^{*}, \Delta \mathrm{E}^{*}\right.$, and browning index (BI)) of different formulas FDT are presented in (Table 1). Data revealed that the different gluten flour affected the value of $b^{*}$, increasing from $29.05 \pm 1.05$ to $31.24 \pm 0.65$, which indicated that strong-gluten flour increased the color yellowness of FDT, but other chroma did not change significantly. BI increased from $109.00 \pm 1.64$ to $124.82 \pm 0.97$ with the gluten content in wheat flour. This observation indicated that more protein participated in the chemical reaction of FDT to promote the browning during the production process. The reason for FDT browning is similar to the browning of flour dough result of the Maillard reactions and caramelization of the exposure to high temperatures $[32,33]$. The $b^{*}, L^{*}$, and $\Delta \mathrm{E}^{*}$ values of FDT with maltitol, lactitol, and sorbitol added were significantly lower than that of sucrose, which was probably because polyol sweeteners are non-reducing substances and hence do not undergo Maillard browning reactions [32]. Compared with palm oil, soybean oil and rapeseed oil have no significant effect on the color change of FDT. 


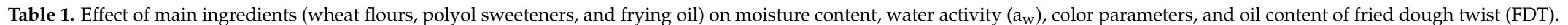

\begin{tabular}{|c|c|c|c|c|c|c|c|c|c|c|}
\hline & \multicolumn{3}{|c|}{ Wheat Flours } & \multicolumn{4}{|c|}{ Polyol Sweeteners } & \multicolumn{3}{|c|}{ Frying Oil } \\
\hline & $\begin{array}{l}\text { Low-Gluten } \\
\text { Flour }\end{array}$ & $\begin{array}{l}\text { Medium-Gluten } \\
\text { Flour }\end{array}$ & $\begin{array}{l}\text { Strong-Gluten } \\
\text { Flour }\end{array}$ & Sucrose & Maltitol & Lactitol & Sorbitol & Palm Oil & Soybean Oil & Rapeseed Oil \\
\hline Moisture content (\%) & $3.05 \pm 0.26 \mathrm{a}$ & $2.88 \pm 0.17 \mathrm{ab}$ & $2.56 \pm 0.20 \mathrm{~b}$ & $3.05 \pm 0.26 \mathrm{a}$ & $3.18 \pm 0.23 a$ & $3.25 \pm 0.24 a$ & $3.03 \pm 0.25 a$ & $3.05 \pm 0.26 a$ & $2.92 \pm 0.27 a$ & $2.88 \pm 0.19 a$ \\
\hline$a *$ & $16.37 \pm 0.14 a$ & $15.81 \pm 0.64 \mathrm{a}$ & $15.69 \pm 0.51 a$ & $16.37 \pm 0.14 a$ & $15.31 \pm 1.18 \mathrm{a}$ & $15.43 \pm 1.04 a$ & $16.69 \pm 0.42 \mathrm{a}$ & $16.37 \pm 0.14 a$ & $16.91 \pm 1.22 \mathrm{a}$ & $14.87 \pm 0.72 \mathrm{a}$ \\
\hline$b^{*}$ & $29.05 \pm 1.05 c$ & $31.84 \pm 0.42 b$ & $32.74 \pm 0.65 a$ & $29.05 \pm 2.45 a$ & $20.41 \pm 2.26 b$ & $22.26 \pm 1.79 b$ & $20.97 \pm 1.42 b$ & $29.05 \pm 2.45 a$ & $30.30 \pm 1.58 \mathrm{a}$ & $32.59 \pm 0.85 a$ \\
\hline $\mathrm{L}^{*}$ & $35.69 \pm 3.16 a$ & $32.71 \pm 0.81 a$ & $32.41 \pm 0.54 a$ & $35.69 \pm 3.16 a$ & $26.78 \pm 2.14 b$ & $29.50 \pm 3.72 b$ & $27.49 \pm 0.52 b$ & $35.69 \pm 3.16 a$ & $34.15 \pm 3.15 a$ & $37.59 \pm 1.31 a$ \\
\hline$\Delta \mathrm{E}^{*}$ & - & $4.12 \pm 0.64 b$ & $4.98 \pm 1.07 \mathrm{~b}$ & - & $12.45 \pm 1.23 a$ & $9.27 \pm 2.06 \mathrm{a}$ & $11.52 \pm 1.43 a$ & - & $2.06 \pm 1.16 \mathrm{~b}$ & $4.29 \pm 1.28 b$ \\
\hline BI & $109.00 \pm 1.64 c$ & $122.08 \pm 1.19 b$ & $124.82 \pm 0.97 \mathrm{a}$ & $109.00 \pm 1.64 a$ & $106.72 \pm 1.48 \mathrm{~b}$ & $105.17 \pm 1.05 b$ & $107.43 \pm 1.69 \mathrm{ab}$ & $109.00 \pm 1.64 a$ & $116.69 \pm 1.70 a$ & $113.75 \pm 1.01 \mathrm{a}$ \\
\hline
\end{tabular}

1 Data are presented as mean values \pm standard deviation. 2 The different lowercase letters represents significant difference in the same column $(* p<0.05)$. 
Hardness and fracturability are important texture properties of FDT, according to the results obtained from the breaking test shown in (Figure 3). The hardness values of the FDT samples increased with the increase in the gluten content of the flour. resulting in the more intensive development of the gluten network, thereby promoting the hardness increase [34,35]. In addition, Graeme Baxter et al. found that the gluten content of flour positively correlated with the hardness properties of the starch gel [36], which indicated that gluten promotes the increase in hardness. However, the fracturability change of FDT is different from the hardness as it decreases with the increase of the gluten content of flour. Different polyol sweeteners also significantly affect the hardness and fracturability of FDT. FDT made with lactitol and sorbitol had lower hardness and fracturability than FDT made with sucrose. While the hardness and fracturability value of FDT made with maltitol is similar to that of FDT made with sucrose. This observation is similar to previous reports on the effect of polyol sweeteners on the hardness and fracturability of cookies [37]. Besides, the hardness and fracturability of the FDT are non-significantly influenced by soybean oil and rapeseed oil.
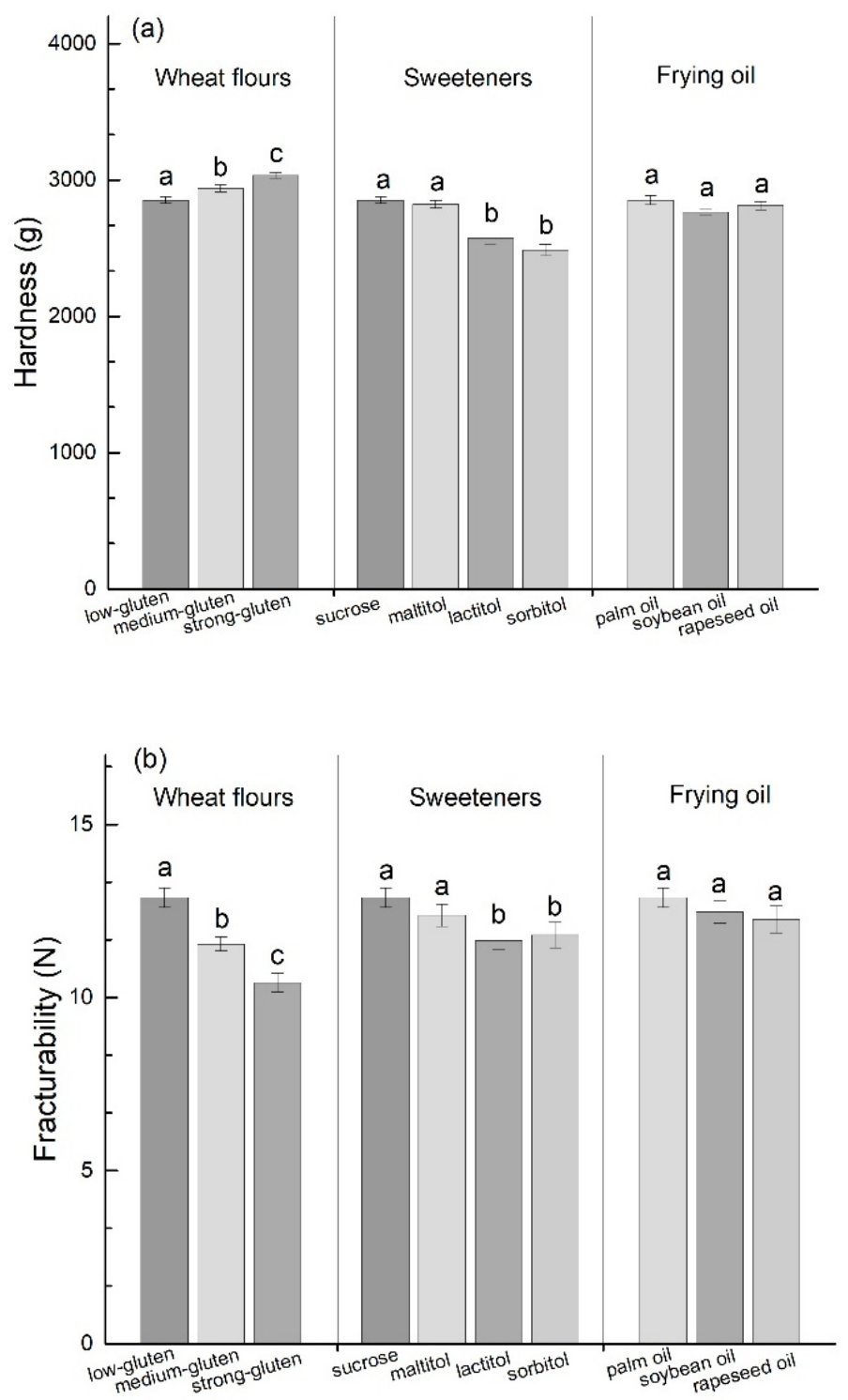

Figure 3. Effect of different ingredients (wheat flours, polyol sweeteners, and frying oil) on hardness (a) and fracturability (b) of fried dough twist (FDT). The different lowercase letters represent significant difference $(p<0.05)$. 
The above results suggest that the content of gluten and polyol sweeteners plays a certain role in changing the physicochemical properties of FDT.

\subsection{Effect Infrared-Assisted Deep-Frying on Fried Dough Twist (FDT)}

Different wheat flours, polyol sweeteners, and frying oil have no significant effect on the oil content of the FDT (Table 1). This indicates that it is difficult to change the main ingredients to reduce the oil content in FDT. Previous studies have shown that pretreatment by using infrared can reduce the oil content of potato chips and chickpea flour-based snack food during deep-frying [22,24]. Therefore, in order to achieve the purpose of controlling the oil content in FDT, we conducted further research on infrared pretreatment combined with deep-frying. According to the above experimental results, low-gluten flour and maltitol were selected as FDT ingredients.

The FDT dough was pretreated by infrared-assisted at different temperatures $\left(80^{\circ} \mathrm{C}\right.$, $100{ }^{\circ} \mathrm{C}$, and $120^{\circ} \mathrm{C}$ ) and time ( $1 \mathrm{~min}, 2 \mathrm{~min}, 3 \mathrm{~min}$, and $4 \mathrm{~min}$ ), and then deep-fried at $160^{\circ} \mathrm{C}$ for $5 \mathrm{~min}$. The results of the oil content in the FDT are shown in (Figure 4a). The data revealed that the oil content in FDT decreases with the increase of infrared-assisted pretreatment temperature and time. When the condition of infrared-assisted pretreatment FDT dough is more than $3 \mathrm{~min}$ at $100{ }^{\circ} \mathrm{C}$ or more than $2 \mathrm{~min}$ at $120^{\circ} \mathrm{C}$, the oil content in FDT no longer decreases significantly. These results confirmed that infrared-assisted pretreatment can significantly reduce the oil content in the FDT under certain conditions. Based on the above experimental data, $100{ }^{\circ} \mathrm{C}$ for $3 \mathrm{~min}$ or $120^{\circ} \mathrm{C}$ for $2 \mathrm{~min}$ can be preliminarily selected as infrared-assisted pretreatment conditions. In addition, the content changes of acrylamide and 5-HMF in the FDT after different infrared-assisted pretreatments were also analyzed (Figure $4 \mathrm{~b}, \mathrm{c}$ ). The data indicated that the formation of acrylamide and $5-\mathrm{HMF}$ in FDT increased with the increase of the pretreatment temperature (or time) of infrared-assisted pretreatment.

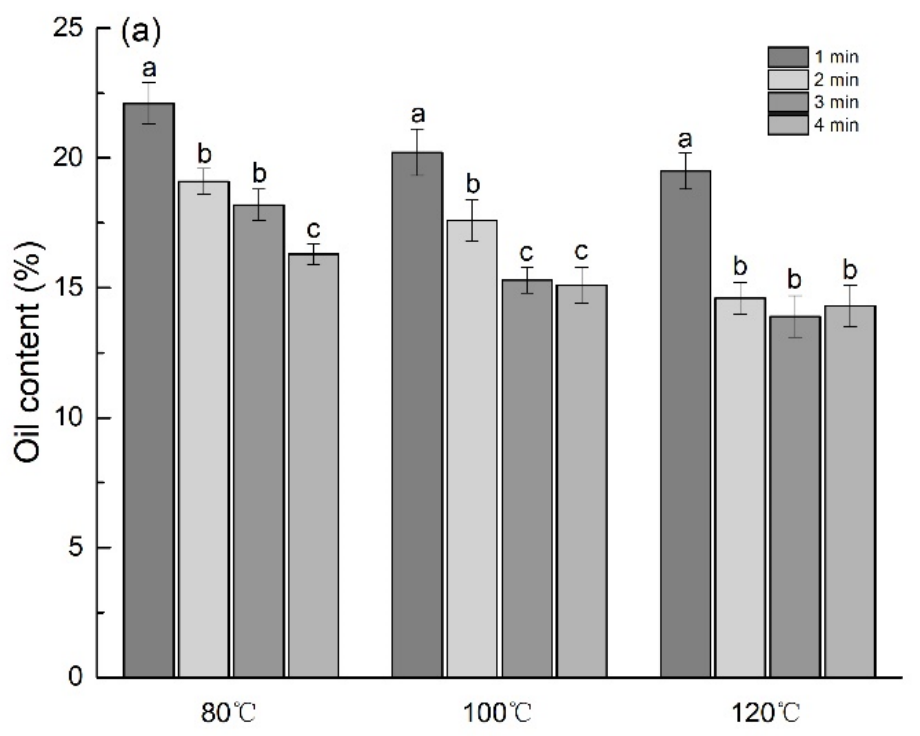

Figure 4. Cont. 

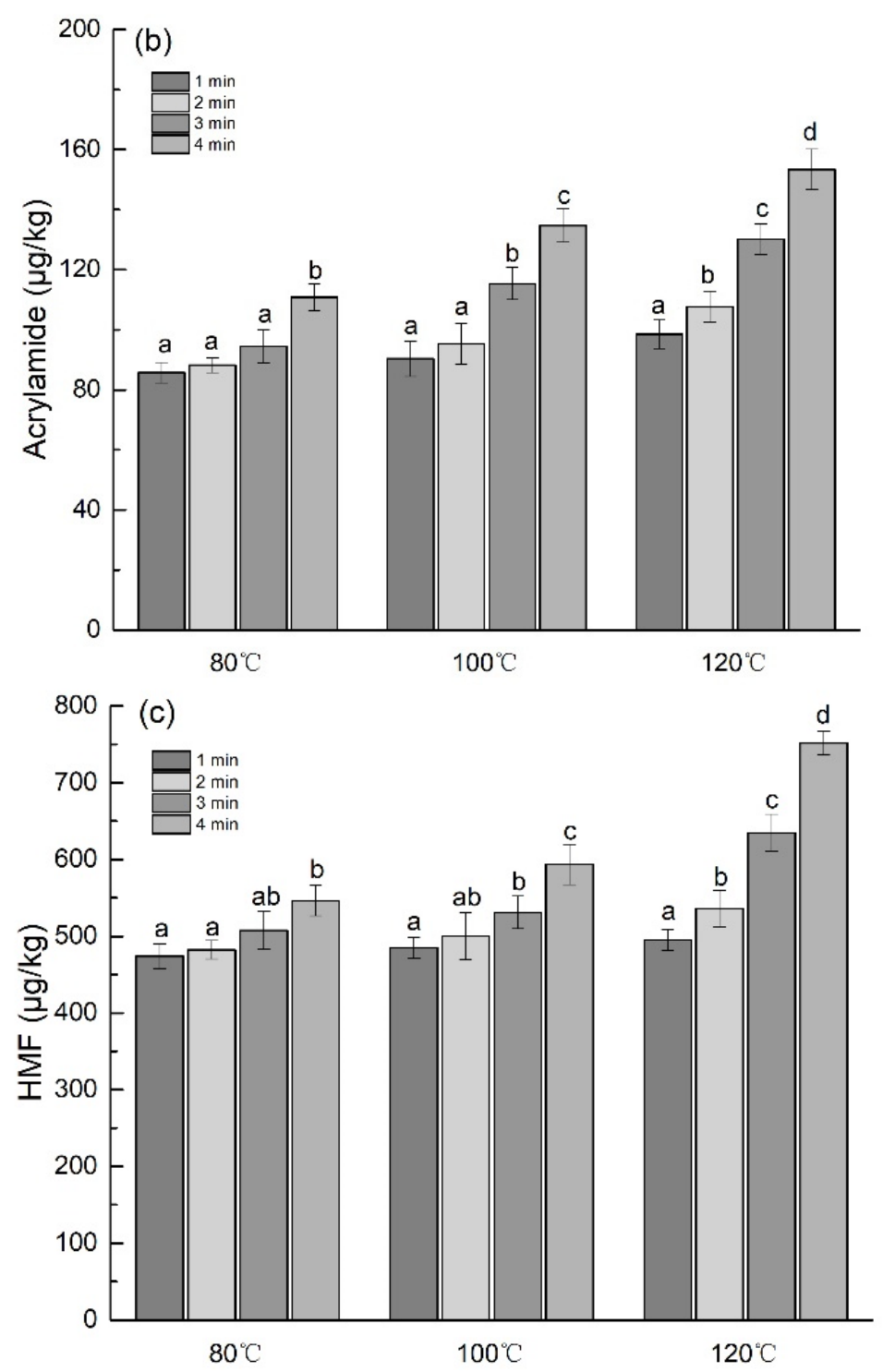

Figure 4. Effect of infrared pretreatment temperature and time on oil content (a), acrylamide (b), and 5-hydroxymethylfurfural (HMF) (c) in FDT. The different lowercase letters represent significant difference $(p<0.05)$.

However, after infrared-assisted pretreatment, the moisture content of FDT decreased with the pretreatment temperature (or time), while the BI, hardness, and fracturability increased significantly (Table 2). This indicated that the infrared-assisted pretreatment combined with the deep-frying process affects the product's organoleptic quality.

To maintain the original organoleptic properties of FDT, based on the preliminary selection of infrared-assisted pretreatment conditions, the effect of deep-frying time on FDT organoleptic properties was further studied. As shown in (Table 3), the data show that the color parameters, hardness, and fracturability of FDT were increased with the increase of deep-frying time. Comparing these data with the deep-frying FDT, it is found that the organoleptic properties of FDT made by infrared-assisted pretreatment (condition at $100{ }^{\circ} \mathrm{C}$ for $3 \mathrm{~min}$ ) combined with deep-frying (condition at $160^{\circ} \mathrm{C}$ for $4 \mathrm{~min}$ ) are more similar to that of FDT. This combined condition maintains the organoleptic properties of FDT to a certain extent. 


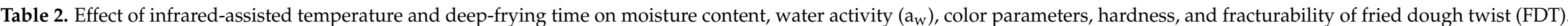

\begin{tabular}{|c|c|c|c|c|c|c|c|c|c|c|}
\hline $\begin{array}{l}\text { Infrared- } \\
\text { Assisted } \\
\text { Temperature }\end{array}$ & $\begin{array}{l}\text { Infrared- } \\
\text { Assisted } \\
\text { Time (min) }\end{array}$ & $\begin{array}{c}\text { Moisture } \\
\text { Content (\%) }\end{array}$ & Water Activity & $a^{*}$ & $\mathbf{b}^{*}$ & $\mathbf{L}^{*}$ & $\Delta \mathrm{E}^{*}$ & BI & Hardness(g) & Fracturability (N) \\
\hline \multirow{4}{*}{$80^{\circ} \mathrm{C}$} & 1 & $3.11 \pm 0.25 \mathrm{a}$ & $0.64 \pm 0.03 a$ & $15.64 \pm 1.13 a$ & $20.41 \pm 0.97 a$ & $41.47 \pm 0.29 a$ & - & $84.45 \pm 2.28 \mathrm{a}$ & $2914.25 \pm 60.74 a$ & $12.56 \pm 0.72 \mathrm{a}$ \\
\hline & 2 & $3.02 \pm 0.32 \mathrm{ab}$ & $0.58 \pm 0.02 a$ & $14.80 \pm 1.08 \mathrm{a}$ & $24.66 \pm 1.75 b$ & $38.20 \pm 0.55 b$ & $5.43 \pm 1.23 b$ & $94.23 \pm 1.37 \mathrm{~b}$ & $3325.73 \pm 38.19 b$ & $12.45 \pm 0.79 a$ \\
\hline & 3 & $2.85 \pm 0.28 \mathrm{ab}$ & $0.59 \pm 0.01 a$ & $14.65 \pm 0.56 a$ & $27.92 \pm 2.32 c$ & $35.76 \pm 0.62 c$ & $9.48 \pm 1.43 c$ & $104.81 \pm 2.35 c$ & $3484.33 \pm 45.28 b$ & $13.15 \pm 0.35 \mathrm{ab}$ \\
\hline & 4 & $2.62 \pm 0.24 \mathrm{~b}$ & $058 \pm 0.03 \mathrm{a}$ & $13.65 \pm 2.60 \mathrm{a}$ & $29.72 \pm 1.28 \mathrm{~d}$ & $33.21 \pm 0.78 c$ & $12.60 \pm 0.95 \mathrm{~d}$ & $115.89 \pm 1.46 \mathrm{~d}$ & $3633.84 \pm 61.32 b$ & $14.03 \pm 0.27 \mathrm{~b}$ \\
\hline \multirow[b]{3}{*}{$100^{\circ} \mathrm{C}$} & 1 & $2.93 \pm 0.23 a$ & $0.60 \pm 0.03 a$ & $15.75 \pm 0.69 a$ & $21.02 \pm 0.43 a$ & $40.05 \pm 1.22 \mathrm{a}$ & $1.55 \pm 1.02 \mathrm{a}$ & $86.66 \pm 2.42 \mathrm{a}$ & $3179.11 \pm 51.72 \mathrm{a}$ & $13.13 \pm 1.34 a$ \\
\hline & 2 & $2.62 \pm 0.41 \mathrm{ab}$ & $0.61 \pm 0.02 \mathrm{a}$ & $14.99 \pm 0.37 b$ & $25.73 \pm 0.15 b$ & $36.78 \pm 0.49 b$ & $6.91 \pm 1.49 b$ & $98.56 \pm 2.37 \mathrm{~b}$ & $3470.09 \pm 31.16 b$ & $12.28 \pm 0.70 \mathrm{a}$ \\
\hline & 3 & $2.76 \pm 0.35 a b$ & $0.56 \pm 0.04 a$ & $14.32 \pm 0.42 \mathrm{c}$ & $28.17 \pm 0.65 c$ & $35.46 \pm 1.32 b$ & $9.90 \pm 1.27 c$ & $106.19 \pm 3.28 c$ & $3691.82 \pm 62.13 c$ & $13.23 \pm 0.14 a$ \\
\hline \multirow{4}{*}{$120^{\circ}$} & 1 & $2.83 \pm 0.27 a$ & $0.58 \pm 0.04 a$ & $14.13 \pm 0.51 \mathrm{a}$ & $22.82 \pm 1.10 a$ & $38.00 \pm 0.77 a$ & $1.97 \pm 0.86 a$ & $90.87 \pm 1.49 a$ & $3195.79 \pm 57.18 \mathrm{a}$ & $12.48 \pm 0.89 a$ \\
\hline & 2 & $2.51 \pm 0.19 a b$ & $0.55 \pm 0.03 a$ & $13.91 \pm 0.75 a$ & $28.72 \pm 0.77 b$ & $39.26 \pm 1.13 a$ & $3.67 \pm 1.30 \mathrm{~b}$ & $99.9 \pm 2.23 b$ & $3533.89 \pm 43.91 b$ & $13.61 \pm 0.79 \mathrm{ab}$ \\
\hline & 3 & $2.45 \pm 0.31 \mathrm{ab}$ & $0.54 \pm 0.05 a$ & $13.91 \pm 0.73 a$ & $33.49 \pm 1.78 c$ & $38.72 \pm 1.29 a$ & $6.68 \pm 1.54 b$ & $112.28 \pm 3.35 c$ & $3624.33 \pm 24.56 c$ & $13.82 \pm 0.38 \mathrm{ab}$ \\
\hline & 4 & $2.21 \pm 0.33 b$ & $0.56 \pm 0.03 a$ & $15.89 \pm 1.20 \mathrm{~b}$ & $35.46 \pm 0.93 c$ & $37.64 \pm 2.09 a$ & $14.64 \pm 1.32 \mathrm{~d}$ & $121.22 \pm 4.64 d$ & $3972.35 \pm 69.88 \mathrm{~d}$ & $14.20 \pm 0.53 b$ \\
\hline
\end{tabular}

1 Data are presented as mean values \pm standard deviation. 2 The different lowercase letters a-d represents significant difference in the same column $\left({ }^{*} p<0.05\right)$.

Table 3. Effect of deep-frying time on color parameters, hardness, and fracturability of fried dough twist (FDT) in different an infrared-assisted condition.

\begin{tabular}{|c|c|c|c|c|c|c|c|c|}
\hline $\begin{array}{l}\text { Infrared-Assisted } \\
\text { Condition }\end{array}$ & $\begin{array}{l}\text { Deep-Frying } \\
\text { Time (min) }\end{array}$ & $a^{*}$ & $\mathbf{b}^{*}$ & $\mathbf{L}^{*}$ & $\Delta \mathrm{E}^{*}$ & BI & Hardness (g) & Fracturability (N) \\
\hline \multirow[b]{2}{*}{$100{ }^{\circ} \mathrm{C}$ for $3 \mathrm{~min}$} & 3 & $14.19 \pm 0.60 \mathrm{a}$ & $23.73 \pm 0.64 a$ & $40.78 \pm 0.68 a$ & - & $89.17 \pm 3.12 a$ & $2914.25 \pm 60.74 a$ & $12.56 \pm 0.22 a$ \\
\hline & 4 & $14.63 \pm 1.32 \mathrm{a}$ & $25.85 \pm 0.58 b$ & $34.78 \pm 0.72 b$ & $6.38 \pm 1.35 a$ & $102.23 \pm 1.32 b$ & $3179.11 \pm 51.72 b$ & $13.13 \pm 0.24 \mathrm{ab}$ \\
\hline \multirow{3}{*}{$120^{\circ} \mathrm{C}$ for $2 \mathrm{~min}$} & 3 & $13.08 \pm 0.83 a$ & $23.89 \pm 0.42 a$ & $42.48 \pm 1.65 a$ & $2.04 \pm 1.52 b$ & $87.09 \pm 2.34 a$ & $3325.73 \pm 38.19 a$ & $12.45 \pm 0.59 a$ \\
\hline & 4 & $14.03 \pm 1.57 \mathrm{a}$ & $26.8 \pm 0.51 b$ & $38.12 \pm 0.91 b$ & $4.07 \pm 1.37 \mathrm{a}$ & $98.04 \pm 2.19 b$ & $3470.09 \pm 31.16 b$ & $12.28 \pm 0.70 \mathrm{ab}$ \\
\hline & 5 & $13.91 \pm 0.75 a$ & $28.72 \pm 0.77 c$ & $39.26 \pm 1.13 b$ & $5.22 \pm 1.28 \mathrm{a}$ & $99.9 \pm 2.23 b$ & $3533.89 \pm 43.91 c$ & $13.61 \pm 0.79 b$ \\
\hline
\end{tabular}

1 Data are presented as mean values \pm standard deviation. 2 The different lowercase letters a-c represents significant difference in the same column $\left({ }^{*} p<0.05\right)$. 


\subsection{Comparison of the Effect of Deep-Frying and Infrared-Assisted Deep-Frying on Fried Dough} Twist (FDT)

The effect of infrared-assisted deep-frying on FDT was studied by comparing different processes on the physicochemical characteristics, oil content, and potentially harmful MRPs of FDT (Table 4). The results indicated that there were significant differences in the moisture content, color, hardness, and fracturability between deep-frying FDT with sucrose and infrared-assisted deep-frying FDT with maltitol. Nevertheless, the BI, hardness, and fracturability of FDT only differ by about $6 \%, 10 \%$, and $2 \%$, respectively. Compared with deep-frying FDT made of sucrose, the amount of acrylamide and HMF in the infrared-assisted deep-frying FDT made with maltitol were reduced by $61.8 \%$ and $63.4 \%$, respectively. Interestingly, the content of acrylamide and HMF in the infraredassisted deep -frying FDT made of maltitol is also lower than that in deep-frying FDT made of maltitol. This must be closely related to shortening the deep-frying time. A total of $27.5 \%$ of oil content was reduced in the infrared-assisted deep-frying FDT made of maltitol compared to that in the deep-frying FDT made of sucrose. It can be seen that changing to low-gluten flour and maltitol as ingredients, combined with infrared-assisted deep-frying process can significantly reduce the acrylamide, HMF, and oil content in FDT at the same time.

Table 4. Moisture content, water activity, color parameter, texture parameters, acrylamide content, 5-(hydroxymethyl)-2-furfural (HMF) content, and oil content in the deep-frying and infrared pretreatment deep-frying fried dough twist (FDT).

\begin{tabular}{cccc}
\hline & $\begin{array}{c}\text { Deep-Frying } \\
\text { (Sucrose) }\end{array}$ & $\begin{array}{c}\text { Deep-Frying } \\
\text { (Maltitol) }\end{array}$ & $\begin{array}{c}\text { Infrared-Assisted } \\
\text { Deep-Frying } \\
\text { (Maltitol) }\end{array}$ \\
\hline Moisture content $(\%)$ & $3.05 \pm 0.26 \mathrm{a}$ & $3.18 \pm 0.23 \mathrm{a}$ & $2.73 \pm 0.29 \mathrm{~b}$ \\
Water activity & $0.61 \pm 0.01 \mathrm{a}$ & $0.64 \pm 0.02 \mathrm{a}$ & $0.59 \pm 0.05 \mathrm{a}$ \\
$\mathrm{a}^{*}$ & $16.37 \pm 0.14 \mathrm{a}$ & $15.31 \pm 1.18 \mathrm{a}$ & $14.63 \pm 1.32 \mathrm{a}$ \\
$\mathrm{b}^{*}$ & $29.05 \pm 1.05 \mathrm{a}$ & $20.41 \pm 2.26 \mathrm{a}$ & $25.85 \pm 0.58 \mathrm{c}$ \\
$\mathrm{L}^{*}$ & $35.69 \pm 3.16 \mathrm{a}$ & $26.78 \pm 2.14 \mathrm{~b}$ & $34.78 \pm 0.72 \mathrm{a}$ \\
$\Delta \mathrm{E}^{*}$ & - & $17.68 \pm 1.78 \mathrm{a}$ & $30.18 \pm 2.28 \mathrm{~b}$ \\
BI & $109.00 \pm 1.64 \mathrm{a}$ & $106.72 \pm 1.48 \mathrm{a}$ & $102.23 \pm 1.32 \mathrm{~b}$ \\
Hardness $(\mathrm{g})$ & $2852.63 \pm 22.51 \mathrm{a}$ & $2922.5 \pm 27.19 \mathrm{~b}$ & $3179.11 \pm 51.72 \mathrm{c}$ \\
Fracturability $(\mathrm{N})$ & $12.89 \pm 0.28 \mathrm{a}$ & $12.38 \pm 1.23 \mathrm{ab}$ & $13.13 \pm 0.24 \mathrm{~b}$ \\
Oil content $(\%)$ & $21.1 \pm 1.4 \mathrm{a}$ & $20.6 \pm 0.8 \mathrm{a}$ & $15.3 \pm 0.5 \mathrm{~b}$ \\
Acrylamide $(\mu \mathrm{g} / \mathrm{kg})$ & $206.1 \pm 87.49 \mathrm{a}$ & $85.68 \pm 13.38 \mathrm{~b}$ & $78.53 \pm 13.52 \mathrm{c}$ \\
HMF $(\mu \mathrm{g} / \mathrm{kg})$ & $1054.19 \pm 29.14 \mathrm{a}$ & $474.08 \pm 26.16 \mathrm{~b}$ & $380.32 \pm 23.36 \mathrm{c}$ \\
\hline
\end{tabular}

1 Data are presented as mean values \pm standard deviation. 2 The different lowercase letters a-c represents significant difference in the same row $\left({ }^{*} p<0.05\right)$.

\section{Conclusions}

Our results suggest that the formation of acrylamide and HMF in FDT made from low-gluten flour and maltitol was significantly reduced. Additionally, it also affected the water content, color, and texture characteristics of FDT, but did not significantly affect the oil content of FDT. We further researched and constructed the processing technology of combining infrared-assisted pretreatment with deep-frying. The oil content in FDT was significantly reduced by the infrared-assisted deep-frying process. Although it is shown that infrared pretreatment could increase the formation of acrylamide and HMF, the processing technology shortened the deep-frying time, resulting in a further reduction in the content of acrylamide and HMF. From these results, it can be concluded that using low-gluten flour and maltitol in the product ingredients, and combining infrared-assisted technology can be used as an effective strategy to simultaneously control acrylamide, HMF, and oil content. Further researches should explore whether consumers perceive sensory quality differences and study the impact of this practice on product shelf life. 
Author Contributions: Conceptualization, Y.Z. and Z.H.; methodology, J.G.; validation, S.Z.; formal analysis, J.G.; investigation, S.Z.; resources, Y.Z.; data curation, S.Z.; writing-original draft preparation, Z.H.; writing—review and editing, Z.H., Y.Z.; supervision, Y.Z.; project administration, Y.Z. and S.W.; funding acquisition, Y.Z. All authors have read and agreed to the published version of the manuscript.

Funding: This research was funded by the National Key R \& D Program of China, grant number 2016YFD0400401.

Institutional Review Board Statement: Not applicable.

Informed Consent Statement: Not applicable.

Data Availability Statement: No new data were created or analyzed in this study. Data sharing is not applicable to this article.

Conflicts of Interest: The authors declare no conflict of interest.

\section{References}

1. Liu, H.; Li, J. Changes in glyoxal and methylglyoxal content in the fried dough twist during frying and storage. Eur. Food Res. Technol. 2014, 238, 323-331. [CrossRef]

2. Zhuang, H.; Zhang, T.; Liu, J.; Yuan, Y. Detection of acrylamide content in traditional Chinese food by high-performance liquid chromatography tandem mass spectrometry method. CyTA J. Food 2012, 10, 36-41. [CrossRef]

3. Müller, R.; Rappert, S. Pyrazines: Occurrence, formation and biodegradation. Appl. Microbiol. Biotechnol. 2010, 85, 1315-1320. [CrossRef]

4. Starowicz, M.; Zieliński, H. How Maillard Reaction Influences Sensorial Properties (Color, Flavor and Texture) of Food Products? Food Rev. Int. 2019, 35, 707-725. [CrossRef]

5. Zhou, P.; Guo, M.; Liu, D.; Liu, X.; Labuza, T.P. Maillard-Reaction-Induced Modification and Aggregation of Proteins and Hardening of Texture in Protein Bar Model Systems. J. Food Sci. 2013, 78, 437-444. [CrossRef]

6. De Oliveira, F.C.; Coimbra, J.S.D.R.; de Oliveira, E.B.; Zuñiga, A.D.G.; Rojas, E.E.G. Food Protein-polysaccharide Conjugates Obtained via the Maillard Reaction: A Review. Crit. Rev. Food Sci. Nutr. 2016, 56, 1108-1125. [CrossRef] [PubMed]

7. Mesias, M.; Holgado, F.; Márquez-Ruiz, G.; Morales, F.J. An investigation of process contaminants' formation during the deep frying of breadcrumbs using a bread coat model. Food Funct. 2016, 7, 1645-1654. [CrossRef] [PubMed]

8. Nguyen, H.T.; Van der Fels-Klerx, H.J.; Peters, R.J.B.; Van Boekel, M.A.J.S. Acrylamide and 5-hydroxymethylfurfural formation during baking of biscuits: Part I: Effects of sugar type. Food Chem. 2016, 192, 575-585. [CrossRef] [PubMed]

9. Žilić, S.; Aktağ, I.G.; Dodig, D.; Filipović, M.; Gökmen, V. Acrylamide formation in biscuits made of different wholegrain flours depending on their free asparagine content and baking conditions. Food Res. Int. 2020, 132, 109109. [CrossRef]

10. Robert, F.; Vuataz, G.; Pollien, P.; Saucy, F.; Alonso, M.-I.; Bauwens, I.; Blank, I. Acrylamide Formation from Asparagine under Low-Moisture Maillard Reaction Conditions. 1. Physical and Chemical Aspects in Crystalline Model Systems. J. Agric. Food Chem. 2004, 52, 6837-6842. [CrossRef]

11. Koszucka, A.; Nowak, A.; Nowak, I.; Motyl, I. Acrylamide in human diet, its metabolism, toxicity, inactivation and the associated European Union legal regulations in food industry. Crit. Rev. Food Sci. 2020, 60, 1677-1692. [CrossRef] [PubMed]

12. Pundir, C.S.; Yadav, N.; Chhillar, A.K. Occurrence, synthesis, toxicity and detection methods for acrylamide determination in processed foods with special reference to biosensors: A review. Trends Food Sci. Technol. 2019, 85, 211-225. [CrossRef]

13. Mesías, M.; Morales, F.J. Effect of Different Flours on the Formation of Hydroxymethylfurfural, Furfural, and Dicarbonyl Compounds in Heated Glucose/Flour Systems. Foods 2017, 6, 14. [CrossRef]

14. Zhang, Z.; Zou, Y.; Wu, T.; Huang, C.; Pei, K.; Zhang, G.; Lin, X.; Bai, W.; Ou, S. Chlorogenic acid increased 5hydroxymethylfurfural formation when heating fructose alone or with aspartic acid at two pH levels. Food Chem. 2016, 190, 832-835. [CrossRef]

15. Polovková, M.; Šimko, P. Determination and occurrence of 5-hydroxymethyl-2-furaldehyde in white and brown sugar by high performance liquid chromatography. Food Control. 2017, 78, 183-186. [CrossRef]

16. Schouten, M.A.; Tappi, S.; Romani, S. Acrylamide in coffee: Formation and possible mitigation strategies-A review. Crit. Rev. Food Sci. 2020, 3807-3821. [CrossRef]

17. Wang, S.; Yu, J.; Xin, Q.; Wang, S.; Copeland, L. Effects of starch damage and yeast fermentation on acrylamide formation in bread. Food Control. 2017, 73, 230-236. [CrossRef]

18. Higley, J.; Kim, J.-Y.; Huber, K.C.; Smith, G. Added versus Accumulated Sugars on Color Development and Acrylamide Formation in French-Fried Potato Strips. J. Agric. Food Chem. 2012, 60, 8763-8771. [CrossRef]

19. Xu, F.; Oruna-Concha, M.-J.; Elmore, J.S. The use of asparaginase to reduce acrylamide levels in cooked food. Food Chem. 2016, 210, 163-171. [CrossRef] [PubMed]

20. Nguyen, H.T.; van der Fels-Klerx, H.J.; van Boekel, M.A.J.S. Acrylamide and 5-hydroxymethylfurfural formation during biscuit baking. Part II: Effect of the ratio of reducing sugars and asparagine. Food Chem. 2017, 230, 14-23. [CrossRef] [PubMed] 
21. Mogol, B.A.; Gokmen, V. Effect of chitosan on the formation of acrylamide and hydroxymethylfurfural in model, biscuit and crust systems. Food Funct. 2016, 7, 3431-3436. [CrossRef] [PubMed]

22. Lumanlan, J.C.; Fernando, W.M.A.D.B.; Karnpanit, W.; Jayasena, V. Effects of food gums and pre-drying on fat content of fabricated fried chips. Int. J. Food Sci. Technol. 2020. [CrossRef]

23. Durán, M.; Pedreschi, F.; Moyano, P.; Troncoso, E. Oil partition in pre-treated potato slices during frying and cooling. J. Food Eng. 2007, 81, 257-265. [CrossRef]

24. Debnath, S.; Bhat, K.K.; Rastogi, N.K. Effect of pre-drying on kinetics of moisture loss and oil uptake during deep fat frying of chickpea flour-based snack food. LWT Food Sci. Technol. 2003, 36, 91-98. [CrossRef]

25. Han, Z.; Gao, J.; Wang, X.; Wang, W.; Dong, J.; Zhang, Y.; Wang, S. Formation and Alterations of the Potentially Harmful Maillard Reaction Products during the Production and Storage of Brown Fermented Milk. Molecules 2019, 24, 272. [CrossRef]

26. Han, Z.; Gao, J.; Li, J.; Zhang, Y.; Yang, Y.; Wang, S. Mitigation of 3-deoxyglucosone and 5-hydroxymethylfurfural in brown fermented milk via an alternative browning process based on the hydrolysis of endogenous lactose. Food Funct. 2019, 10, 2022-2029. [CrossRef]

27. Roldan, M.; Loebner, J.; Degen, J.; Henle, T.; Antequera, T.; Ruiz-Carrascal, J. Advanced glycation end products, physico-chemical and sensory characteristics of cooked lamb loins affected by cooking method and addition of flavour precursors. Food Chem. 2015, 168, 487-495. [CrossRef] [PubMed]

28. Carvalho, M.J.; Perez-Palacios, T.; Ruiz-Carrascal, J. Physico-chemical and sensory characteristics of freeze-dried and airdehydrated yogurt foam. LWT Food Sci. Tech. 2017, 80, 328-334. [CrossRef]

29. Claus, A.; Schreiter, P.; Weber, A.; Graeff, S.; Herrmann, W.; Claupein, W.; Schieber, A.; Carle, R. Influence of Agronomic Factors and Extraction Rate on the Acrylamide Contents in Yeast-Leavened Breads. J. Agric. Food Chem. 2006, 54, 8968-8976. [CrossRef] [PubMed]

30. Psimouli, V.; Oreopoulou, V. The effect of alternative sweeteners on batter rheology and cake properties. J. Sci. Food Agric. 2012, 92, 99-105. [CrossRef] [PubMed]

31. Tapia, M.S.; Alzamora, S.M.; Chirife, J. Effects of Water Activity $\left(\mathrm{a}_{\mathrm{w}}\right)$ on Microbial Stability as a Hurdle in Food Preservation. In Water Activity in Foods: Fundamentals and Applications, 2nd ed.; Barbosa-Cánovas, G.V., Fontana, A.J., Jr., Eds.; Wiley Blackwell: Chicago, IL, USA, 2020; pp. 323-355.

32. Zoulias, E.I.; Oreopoulou, V.; Kounalaki, E. Effect of fat and sugar replacement on cookie properties. J. Sci. Food Agric. 2002, 82, 1637-1644. [CrossRef]

33. Purlis, E. Browning development in bakery products-A review. J. Food Eng. 2010, 99, 239-249. [CrossRef]

34. Raymundo, A.; Fradinho, P.; Nunes, M.C. Effect of Psyllium fibre content on the textural and rheological characteristics of biscuit and biscuit dough. Bioact. Carbohyd. Diet. Fibre 2014, 3, 96-105. [CrossRef]

35. Ajila, C.M.; Leelavathi, K.; Prasada Rao, U.J.S. Improvement of dietary fiber content and antioxidant properties in soft dough biscuits with the incorporation of mango peel powder. J. Cereal Sci. 2008, 48, 319-326. [CrossRef]

36. Baxter, G.; Blanchard, C.; Zhao, J. Effects of glutelin and globulin on the physicochemical properties of rice starch and flour. J. Cereal Sci. 2014, 60, 414-420. [CrossRef]

37. Gong, S.; Xu, B.; Gu, X.; Li, W.; Yu, Y.; Zhang, W.; Wang, Z. Study on the effects of sugar alcohols and Angelica keiskei flour on cookie quality, antioxidant, and nutrition. Cereal Chem. 2020, 97, 714-722. [CrossRef] 